\title{
PEMBUATAN BIODIESEL DARI BIJI NYAMPLUNG
}

\section{(The Manufacture of Biodiesel from Nyamplung Seed)}

\author{
Oleh/By : \\ R. Sudradjat, Sahirman \& D. Setiawan
}

\begin{abstract}
The aim of this experiment is to produce biodiesel using nyamplung (Callophyllum inophyllum Linn) that could meet the SNI standard of biodiesel. Nyamplung is a low grade raw material for making biodiesel due to its high free fatty acid (FFA 29\%). During transesterification reaction, FFA is converted into soap and able to reduce biodiesel yield of about $30 \%$. So, the most important step in this experiment is to reduce the FFA content down to about $2 \%$ in order to accelerate transesterification reaction properly.

This experiment consists of pretreatment, degumming, esterification followed by transesterification reaction. Esterification process aims to find the optimum of methanol-FFA mol ratio, HClpertcentage and reaction temperature. Esterification temperature used was 40,50,60 and $80^{\circ} \mathrm{C}$, mol ratio of methanol-HCl are $0: 1$ until $50: 1$, which consists of 11 variable levels, while HClpercentage consists of 7 level starting from 0 to $18 \%$. Optimation analysis for esterification used surface respons methode according to Montgomery (1991) and Box (1978).

The results shown that optimum esterification process obtained at temperature of $60^{\circ} \mathrm{C}, \mathrm{HCl}$ of 6 percent and methanol-FFA mol ratio of 20:1, reaction time 1 hour and rotating speed $400 \mathrm{rpm}$. At this condition the FFA was reduced from $28.7 \%$ to $4.7 \%$. Biodiesel produced has not been stable yet since acid number was around $0.6172-1.8403$ $\mathrm{mg} \mathrm{KOH/gram,} \mathrm{viscosity} \mathrm{at} 40^{\circ} \mathrm{C}$ is around 8.1 - $8.4 \mathrm{cp}(8.67$ - $8.99 \mathrm{cSt}$ ). Metil ester of biodiesel comprised of methyl palmitat $17.29 \%$, metbyl stearat $23.55 \%$, metbyl oleat $36.67 \%$ and methyl linoleat $22.49 \%$. Optimation using surface respons method obtained reaction equation regression of the FFA at the end of esterification is $(Y)=14,6349$ $0,36339 \mathrm{R}-0,309218 \mathrm{~K}-0,195846 \mathrm{~T}+0,00847999 \mathrm{R} 2+0,0279677 \mathrm{~K} 2+0,00194431 \mathrm{~T} 2-0,00352917 \mathrm{RK}-$ 6,19167E-04RT+0,00224167KS.
\end{abstract}

Keywords: Nyamplung oil, free fatty acid, degumming, esterification, transesterification

\begin{abstract}
ABSTRAK
Penelitian ini bertujuan untuk menghasilkan biodiesel dengan bahan baku minyak nyamplung (Callophyllum inophyllum Linn) yang kualitasnya sesuai dengan persyaratan Standar Nasional Indonesia (SNI). Biji nyamplung umumnya berkualitas rendah karena kadar asam lemak bebasnya (FFA) tinggi, yaitu mencapai 29\%. Pada proses transesterifikasi FFA akan diubah menjadi sabun/gel yang bisa mengurangi rendemen biodiesel sampai 30\%. Oleh karena itu, salah satu tahapan penting dalam penelitian ini adalah menurunkan kadar FFA dari minyak nyamplung sampai sekitar $2 \%$ agar proses transesterifikasi dapat berlangsung dengan baik.

Penelitian ini meliputi perlakuan pendahuluan dengan proses degumming, proses esterifikasi dan proses transesterifikasi. Optimasi proses esterifikasi dilakukan dengan mencari kondisi optimum penggunaan rasio mol metanol-FFA, persen asam klorida sebagai katalis dan suhu esterifikasi. Suhu esterifikasi yang digunakan adalah $40,50,60$ dan $80^{\circ} \mathrm{C}$, rasio mol metanol yang digunakan adalah $0: 1$ sampai 50 : 1 yang terbagi menjadi 11 taraf percobaan dan konsentrasi katalis $\mathrm{HCl}$ teknis yang
\end{abstract}


digunakan adalah 0 - 18\% yang terbagi menjadi 7 taraf percobaan. Optimasi proses esterifikasi dilakukan dengan menggunakan metode permukaan respon (Montgomery, 1991 dan Box, 1978).

Hasil penelitian menunjukkan proses esterifikasi minyak nyamplung yang optimum diperoleh pada suhu $60^{\circ} \mathrm{C}$, asam klorida $6 \%$ dan rasio mol metanol-FFA $20: 1$, lama reaksi 1 jam dengan kecepatan pengadukan $400 \mathrm{rpm}$. Pada kondisi tersebut dapat menurunkan kandungan asam lemak bebas dari $28,7 \%$ menjadi $4,7 \%$. Biodiesel yang dihasilkan mempunyai kualitas yang belum stabil dengan bilangan asam berkisar antara $0,6172-1,8403 \mathrm{mg} \mathrm{KOH} /$ gram dan viskositas pada suhu $40^{\circ} \mathrm{C}$ adalah 8,1 - 8,4 cp $(8,67-8,99 \mathrm{cSt})$. Komposisi metil ester biodiesel tersebut adalah metil palmitat $17,29 \%$, metil stearat $23,55 \%$, metil oleat $36,67 \%$ dan metil linoleat $22,49 \%$.

Optimasi dengan metode respon permukaan menghasilkan model persamaan reaksi $=$ Kadar FFA pada akhir esterifikasi adalah $(\mathrm{Y})=14,6349-0,36339 \mathrm{R}-0,309218 \mathrm{~K}-0,195846 \mathrm{~T}+0,00847999 \mathrm{R} 2$ $+0,0279677 \mathrm{~K} 2+0,00194431 \mathrm{~T} 2-0,00352917 \mathrm{RK}-6,19167 \mathrm{E}-04 \mathrm{RT}+0,00224167 \mathrm{KS}$.

Kata kunci: Minyak nyamplung, asam lemak bebas, degumming, esterifikasi, transesterifikasi

\section{PENDAHULUAN}

Kebutuhan solar Indonesia dari tahun ke tahun terus naik, pada tahun 1995 sebesar 15,84 miliar liter, tahun 2000 sebesar 21,39 miliar liter, tahun 2005 sebesar 27,05 miliar liter dan pada tahun 2010 diperkirakan akan meningkat menjadi 34,71 miliar liter (Reksowardoyo, 2005). Pemerintah Indonesia mentargetkan pada tahun 2005 - 2010 memproduksi biodiesel 2\% dari konsumsi solar $(0,72 \mathrm{KL})$ dan pada tahun 2016 - 2025 memproduksi 5\% dari konsumsi solar yaitu sekitar (4,7 juta KL (PP No 5 tahun 2006). Indonesia memiliki banyak jenis tanaman penghasil minyak yang dapat digunakan sebagai bahan baku biodiesel, akan tetapi sebagian minyak nabati memiliki kualitas jelek karena kandungan asam lemak bebas (FFA) yang tinggi. Salah satu jenis minyak tersebut adalah minyak minyak nyamplung (bintangur) yang kadar FFA nya sekitar 29\%.

Menurut Martawijaya et al. (1981), nyamplung (Callophyllum inophyllum Linn) mempunyai nama daerah lain seperti bintangor, mentangur, penanga, bunut, punaga, bataoh, bentangur, butoo, jampelung, jinjit, mahadingan, maharunuk, betau, bintula, dinggale, pude, wetai dan lain-lain serta daerah penyebarannya di Indonesia meliputi Sumatera Barat, Riau, Jambi, Sumatera Selatan, Lampung, Jawa, Kalimantan Barat, Kalimantan Tengah, Sulawesi, Maluku dan Nusa Tenggara Timur. Berdasarkan pengamatan di Kebumen, nyamplung banyak tumbuh di 6 kecamatan khususnya di daerah dekat pantai yaitu kecamatan Ambal, Mirit, Bulus Pesantren, Klirong, Puring dan Petanahan. Biji bintangur mempunyai kadar minyak yang sangat tinggi yaitu 75\% (Dweek dan Meadowsi, 2002) dan 71,4\% (Nijverheid dan Handel dalam Heyne, 1987). Menurut Heyne (1987), inti biji mengandung air 3,3\% dan minyak 71,4\%. Greshoff dalam Heyne (1987) menyatakan bahwa kadar minyak biji bintangur 55\% pada inti biji yang segar dan 70,5\% pada biji yang benar-benar kering. Minyak bintangur di beberapa daerah digunakan untuk penerangan (Dweek dan Meadowsi, 2002) dan (Lele, 2005).

Minyak nyamplung tidak bisa diproses menjadi biodiesel tanpa perlakuan esterifikasi terlebih dahulu. Perlakuan netralisasi tidak memungkinkan karena akan terjadi kehilangan minyak yang sangat tinggi minimal sebesar kadar FFA yang ada di dalam minyak (Sudradjat, 
2006). Menurut Tyson (2004), minyak atau lemak yang mengandung FFA 10\% dapat menurunkan rendemen biodiesel hingga mencapai 30\%. Minyak yang mengandung kadar FFA yang tinggi akan membentuk sabun pada proses produksi biodiesel, sehingga akan menyulitkan proses pencucian dan memungkinkan hilangnya produk (Canakci dan Van Gerpen, 2001). Reaksi esterifikasi dipengaruhi oleh beberapa faktor diantaranya adalah jumlah pereaksi (metanol) asam lemak bebas, waktu reaksi, suhu, konsentrasi katalis dan kadar air pada minyak. Menurut Sudradjat et al. (2005), perlakuan terbaik proses esterifikasi minyak jarak diperoleh pada penggunaan katalis $\mathrm{HCl}$ 1\% (v/v), waktu reaksi 120 menit dan jumlah metanol sebanyak $10 \%(\mathrm{v} / \mathrm{v})$.

Menurut Canakci dan Van Gerpen (2001), esterifikasi terhadap minyak kedele yang mengandung FFA 20\% dengan menggunakan rasio mol metanol: FFA = 9:1 yang dilakukan pada suhu $60^{\circ} \mathrm{C}$ selama 1 jam dan katalis asam sulfat 5\% dari FFA dapat menurunkan bilangan asam dari 41,33 menjadi 1,77. Sedangkan apabila kadar FFA awal 40\% (bilangan asam 91,73), setelah esterifikasi bilangan asam menjadi 18,82. Menurut Canakci et al. (2003), esterifikasi dengan katalis asam terhadap minyak FFA tinggi dan telah dikeringkan terlebih dahulu memerlukan alkohol tinggi $20: 1$, suhu $60^{\circ} \mathrm{C}$, waktu 1 - 2 jam. Apabila suhu dinaikan menjadi $135^{\circ} \mathrm{C}$, maka waktu dapat dipersingkat menjadi 45 menit. Lemak dengan FFA 39,6\% dilakukan esterifikasi dengan 10\% asam sulfat dan rasio mol metanol $20: 1$ yang keduanya dihitung berdasarkan jumlah FFA, diesterifikasi selama 1 jam pada suhu $55-60^{\circ} \mathrm{C}$ menghasilkan minyak dengan bilangan asam 6,96 $\mathrm{mgKOH} / \mathrm{g}(\mathrm{FFA}=3,5 \%)$ apabila setelah proses tersebut dilakukan pengendapan, kemudian bagian bawah diesterifikasi kembali dengan 10\% asam sulfat dan rasio mol metanol $40: 1$ dari jumlah FFA selama 1 jam pada suhu $55-60^{\circ} \mathrm{C}$, maka diperoleh FFA kurang dari $1 \%$ dengan bilangan asam 1,54 mg $\mathrm{KOH} / \mathrm{g}$ (Canakci dan Van Gerpen, 2003).

Transesterifikasi minyak kedele dilakukan dengan $\mathrm{NaOH} 1 \%$, temperatur $60^{\circ} \mathrm{C}$, rasio molar minyak metanol 6:1 (Freedman et al., 1984). Minyak sawit dilakukan transesterifikasi dengan katalis $\mathrm{KOH} 1 \%$, temperatur $60^{\circ} \mathrm{C}$, rasio metanol minyak $6: 1$, waktu 30 menit dengan reaktor batch menghasilkan biodiesel dengan konversi 90 - 98\% (Darnoko dan Cheryan, 2000). Proses transesterifikasi minyak nabati dilakukan dengan menggunakan $\mathrm{KOH}$ atau $\mathrm{NaOH} 0,5-1 \%$, temperatur $60-80^{\circ} \mathrm{C}$, tekanan 1 atmosfer, rasio molar metanol-minyak $6: 1$ dan dengan pengadukan 5 - 10 menit setelah penambahan metanol (Lele, 2005). Minyak kedele dilakukan transesterifikasi dengan rasio metanol-minyak $6: 1, \mathrm{NaOH} 2 \%$, waktu 3 menit (Mao et al., 2004). Proses transesterifikasi minyak jarak pagar dilakukan pada $\mathrm{NaOH}$ 0,5\%, suhu $60^{\circ} \mathrm{C}$, waktu 30 menit dan metanol 10\% (Sudradjat et al., 2005). Menurut Canakci dan Van Gerpen (2003), transesterifikasi terhadap minyak yang mempunyai bilangan asam $1,54 \mathrm{mgKOH} / \mathrm{g}$ dilakukan dengan menggunakan katalis $\mathrm{NaOCH} 30,82 \%$ dengan rasio metanol minyak 6:1 yang keduanya dihitung dari jumlah minyak, suhu $55-60^{\circ} \mathrm{C}$, waktu 1 jam, kemudian dilanjutkan dengan pencucian sebanyak empat kali dan setiap kali pencucian menggunakan air panas bersuhu $60^{\circ} \mathrm{C}$ sebanyak $50 \%$ dari berat ester.

Berdasarkan hasil penelitian Sudradjat dan Setiawan (2003), dapat diketahui bahwa proses esterifikasi-transeterifikasi (estrans) terbukti berhasil mengkonversi asam lemak bebas, berupa trigliserida yang ada di dalam minyak bintangur secara maksimal menjadi metil ester (biodiesel). Dengan proses baku yaitu transesterifikasi, konversi asam lemak tidak berhasil karena tingginya kadar asam lemak bebas (FFA). Variasi konsentrasi metanol berpengaruh terhadap bilangan asam, kerapatan dan kekentalan. Penurunan bilangan asam dan kekentalan 
terjadi secara bermakna, sehingga memenuhi kriteria kualitas biodiesel. Konsentrasi metanol yang optimal adalah 40\%, hal tersebut sangat tinggi oleh karena itu perlu ditingkatkan efisiensi melalui beberapa perubahan pada perlakuan.

\section{METODOLOGI}

\section{A. Lokasi}

Penelitian dilaksanakan di Laboratorium Kimia dan Energi, Pusat Litbang Hasil Hutan Bogor dan Laboratorium SBRC (Surfactan \& Bioenergy Research Centre) IPB Bogor, yang meliputi persiapan bahan baku, pengujian/analisis komponen dan karakteristik minyak nyamplung serta biodiesel dari biji nyamplung.

\section{B. Bahan dan Alat}

Biji nyamplung (Callophyllum inophyllum Linn) yang digunakan untuk penelitian berasal dari daerah Kebumen Jawa Tengah. Bahan kimia yang digunakan antara lain metanol, etanol, asam klorida, natrium hidroksida, indikator phenolphtaelin, asam phosphat, air suling dan bahan kimia lainnya.

Peralatan yang digunakan yaitu satu rangkaian reaktor esterifikasi yang terdiri atas labu mulut/leher dua, pendingin balik, termometer, pengaduk, statif, klem penjepit dan hot plate stirer, pompa vakum, alat distilasi, erlenmeyer, tabung reaksi, desikator, labu ukur, timbangan digital, pipet, corong pemisah, buret, hot plate, pengaduk (stirrer) dan lain-lain.

\section{Prosedur Kerja}

Minyak nyamplung diproses menjadi biodiesel melalui beberapa tahapan yaitu degumming, esterifikasi dan transesterifikasi.

\section{Degumming}

Degumming bertujuan untuk menghilangkan kotoran yang ada di dalam minyak. Minyak disaring dengan alat penyaring vakum pada kondisi hangat. Hasil proses penyaringan dilakukan degumming dengan cara ditimbang 500 gram minyak kemudian dipanaskan di atas hotplate hingga mencapai suhu $80^{\circ} \mathrm{C}$ sambil diaduk dengan menggunakan magnetik stirrer. Larutan asam fosfat konsentrasi 20\% ditambahkan sebanyak 0,2 - 0,3\% (v/w) dan diaduk selama 15 menit. Kemudian minyak dimasukkan dalam corong pemisah $500 \mathrm{ml}$ dan ditambahkan air hangat dengan cara penyemprotan. Corong pemisah digoyang sebentar agar air menyebar mengikat gum lalu didiamkan agar air dengan gum yang terikat turun dan terpisah dari minyak. Penyemprotan air dilakukan sampai air buangan pada kisaran pH 6,5 - 7 . Minyak hasil proses degumming dikeringkan dengan pemanasan pada suhu $80^{\circ} \mathrm{C}$ disertai vakum selama 20 menit dilanjutkan dengan pengeringan vakum selama 10 menit.

\section{Esterifikasi}

Sebanyak $50 \mathrm{ml}$ minyak nyamplung dimasukkan dalam erlemeyer labu bermulut ganda $500 \mathrm{ml}$, ditambahkan metanol dengan rasio mol tertentu dan $\mathrm{HCl}$ teknis dengan konsentrasi 
tertentu. Labu mulut ganda dipasang pada kondensor untuk mengkondensasi uap metanol agar masuk kembali kedalam erlenmeyer. Reaksi dilakukan pada suhu $60^{\circ} \mathrm{C}$ selama 1 jam. Setelah proses esterifikasi selesai, campuran dimasukkan dalam tabung reaksi, diendapkan selama 8 jam dan kemudian diukur kadar FFA nya pada lapisan bawah.

\section{Transesterifikasi}

Sebanyak $200 \mathrm{ml}$ minyak nyamplung hasil esterifikasi dimasukkan dalam labu bermulut ganda $500 \mathrm{ml}$, ditambahkan metanol dengan rasio mol tertentu dan didalam metanol dilarutkan $\mathrm{NaOH}$ teknis Labu mulut ganda dipasang pada kondensor untuk mengkondensasi uap metanol agar masuk kembali ke dalam erlemeyer. Reaksi dilakukan pada suhu $60^{\circ} \mathrm{C}$ selama 1 jam. Setelah proses transesterifikasi selesai, campuran dimasukkan dalam corong pemisah, kemudian diendapkan semalam. Setelah 12 jam gliserol akan mengendap pada bagian bawah corong pemisah sehingga mudah untuk dipisahkan. Biodiesel yang terbentuk selanjutnya dicuci dengan air panas sampai $\mathrm{pH}$ netral dan dikeringkan dengan pemanasan pada suhu $80^{\circ} \mathrm{C}$ disertai vakum selama 20 menit dilanjutkan dengan pengeringan vakum pada suhu $90^{\circ} \mathrm{C}$ selama 10 menit.

\section{Rancangan Percobaan dan Pengolahan Data}

Rancangan percobaan yang digunakan dalam penelitian ini terdiri dari:

1. Percobaan pengaruh perlakuan suhu esterifikasi, rasio mol metanol dan konsentrasi katalis terhadap kadar asam lemak bebas akhir esterifikasi, masing-masing dilakukan secara terpisah dengan menggunakan rancangan acak lengkap (RAL) dengan analisis keragaman satu arah dan untuk mengetahui taraf perlakuan yang berbeda digunakan uji Duncan. Suhu esterifikasi yang digunakan adalah 40, 50, 60 dan $80^{\circ} \mathrm{C}$, rasio mol metanol yang digunakan adalah 0 : 1 - 50:1 yang terbagi menjadi 11 taraf percobaan dan konsentrasi katalis $\mathrm{HCl}$ teknis yang digunakan adalah $0-18 \%$ yang terbagai menjadi 7 taraf percobaan.

2. Optimasi proses esterifikasi dilakukan dengan menggunakan metode permukaan respon (Montgomery, 1991 dan Box, 1978) dengan input variabel masing-masing yaitu rasio mol metanol (taraf percobaan $10: 1 ; 20: 1$ dan $30: 1$ ), katalis $\mathrm{HCl}$ teknis (taraf percobaan $3 \%, 6 \%$ dan $9 \%$ ) dan suhu esterifikasi (taraf percobaan $45^{\circ} \mathrm{C}, 60^{\circ} \mathrm{C}$ dan $75^{\circ} \mathrm{C}$ ). Optimasi kondisi proses percobaan didapatkan berdasarkan model persamaan yang telah teruji.

\section{HASILDAN PEMBAHASAN}

\section{A. Karakterisasi Minyak Nyamplung}

Hasil analisa karakteristik minyak nyamplung yang berasal dari Kebumen ditampilkan pada Tabel 1. Minyak nyamplung tersebut mempunyai kualitas jelek karena mengandung kadar asam lemak bebas yang sangat tinggi mencapai 29,53\% setara dengan bilangan asam $59,94 \mathrm{mg} \mathrm{KOH} / \mathrm{g}$ minyak. 
Tabel1. Karakteristik minyak nyamplung

Table 1. Characteristics of nyamplung oil

\begin{tabular}{|l|c|c|}
\hline \multicolumn{1}{|c|}{ Jenis analisa (Analyses) } & Satuan (Unit) & Hasil (Value) \\
\hline 1. Air (Moisture) & $\%$ & 0,25 \\
\hline 2. Densitas (Density) & $\mathrm{G} / \mathrm{ml}$ & 0,944 \\
\hline 3. Kekentalan (Viscosity) & $\mathrm{Cp}$ & 21,97 \\
\hline 4. Bilangan asam (Acid number) & $\mathrm{mg} \mathrm{KOH} / \mathrm{g}$ & 59,94 \\
\hline 5. Asam lemak bebas (Free fatty acid) & $\%$ & 29,53 \\
\hline 6. Bilangan penyabunan (Saponification number) & $\mathrm{mg} \mathrm{KOH} / \mathrm{g}$ & 198,1 \\
\hline 7. Bilangan iod (Iod number) & $\mathrm{mg} / \mathrm{g}$ & 86,42 \\
\hline
\end{tabular}

Minyak nyamplung tersebut tidak bisa langsung dibuat biodiesel, karena selain kotor juga mempunyai kadar FFA sangat tinggi. Agar dapat diproses menjadi biodiesel, minyak tersebut harus dibersihkan dengan proses degumming terlebih dahulu dan diturunkan kadar FFAnya dengan proses esterifikasi. Penurunan kadar FFA dengan proses netralisasi tidak mungkin, karena hasil penelitian pendahuluan menunjukkan banyaknya kehilangan minyak karena proses penyabunan.

Minyak nyamplung mengandung asam lemak yang terdiri asam lemak jenuh (tidak mempunyai ikatan rangkap) dan asam lemak tidak jenuh (mempunyai ikatan rangkap). Komposisi asam lemak penyusun minyak nyamplung dibanding komposisi asam lemak minyak nabati lainnya dapat dilihat pada Tabel 2 .

Tabel2. Komposisi asam lemak minyak nyamplung dibandingkan minyak nabati lain

Table 2. Fatty acid composition of nyamplung compare with other vegetable oils

\begin{tabular}{|l|c|c|c|c|}
\hline $\begin{array}{c}\text { Komponen } \\
\text { (Component) }\end{array}$ & $\begin{array}{c}\text { Minyak } \\
\text { nyamplung } \\
\text { (Callophyllum oil) a) }\end{array}$ & $\begin{array}{c}\text { Minyak jarak } \\
\text { pagar } \\
\text { (Jatropha oil) b) }\end{array}$ & CPO c) & $\begin{array}{c}\text { Minyak kedele } \\
\text { (Soybean oil) d) }\end{array}$ \\
\hline Asam miristat (C 14) & 0,09 & - & 0,7 & 0,1 \\
\hline Asam palmitat (C 16) & 15,89 & 11,9 & 39,2 & 10,2 \\
\hline Asam stearat (C 18) & 12,30 & 5,2 & 4,6 & 3,8 \\
\hline Asam oleat (C 18:1) & 48,49 & 29,9 & 41,4 & 22,8 \\
\hline Asam linoleat (C 18:2) & 20,70 & 46,1 & 10,5 & 51,0 \\
\hline Asam linolenat (C 18:3) & 0,27 & 4,7 & 0,3 & 6,8 \\
\hline Asam arachidat (C 20) & 0,94 & - & - & 0,28 \\
\hline Asam erukat (C 20:1) & 0,72 & - & - & 0,2 \\
\hline
\end{tabular}

Keterangan (Remarks) : a = Hasil analisis (Results of experiment); b = Haas dan Mittelbach 2000; $\mathrm{c}=$ Darnoko, 2005; d = Hui, 1996 
Minyak nyamplung tersusun oleh empat jenis asam lemak utama yaitu asam palmitat $(16 \%)$, asam stearat $(12 \%)$, asam oleat $(49 \%)$ dan asam linoleat $(21 \%)$. Total keseluruhan dari empat jenis asam lemak utama tersebut mencapai 97\%. Jumlah empat jenis asam lemak utama yaitu asam palmitat, asam stearat, asam oleat dan asam linoleat pada minyak jarak pagar $92 \%$, minyak kelapa sawit 94\% dan minyak kedele 85\%. Dengan demikian, minyak nyamplung mempunyai kemiripan dengan minyak-minyak tersebut. Minyak jarak pagar, CPO dan minyak kedele sudah terbukti dapat digunakan sebagai bahan baku pembuatan biodiesel dan karena minyak nyamplung mempunyai kemiripan, maka diduga minyak nyamplung dapat digunakan sebagai bahan baku pembuatan biodiesel.

\section{B. Esterifikasi}

\section{Pengaruh suhu}

Esterifikasi dipengaruhi oleh kondisi minyak, waktu, suhu, kadar metanol dan katalis. Kadar FFA akhir esterifikasi yang dilakukan pada rasio mol metanol $30: 1$, katalis $\mathrm{HCl}$ 6\%, waktu 60 menit dan kecepatan pengadukan $400 \mathrm{rpm}$ pada berbagai suhu esterifikasi dapat dilihat pada Tabel 3 dan Gambar 1.

Tabel 3. Rata-rata kadar FFA akhir esterifikasi pada berbagai suhu Table 3. FFA average value in the end of esterification at different temperature

\begin{tabular}{|c|c|}
\hline $\begin{array}{c}\text { Suhu esterifikasi } \\
\text { (Esterification temperature), }{ }^{\circ} \mathrm{C}\end{array}$ & $\begin{array}{c}\text { FFA setelah esterifikasi } \\
\text { (FFA after esterification), \% }\end{array}$ \\
\hline 50 & $5,4602 \mathrm{a}$ \\
\hline 60 & $5,0519 \mathrm{~b}$ \\
\hline 70 & $4,9735 \mathrm{bc}$ \\
\hline 80 & $4,7203 \mathrm{c}$ \\
\hline
\end{tabular}

Keterangan (Remarks): Angka dengan kode huruf sama tidak berbeda nyata pada $\alpha 5 \%$ (Value with the same letter code is not significant at a 5\%). Bahan baku minyak nyamplung hasil degumming dengan kadar FFA 28,7\% (Raw material is callophyllum oil which contains FFA of 28.7\%)

Kadar FFA akhir esterifikasi menunjukkan perbedaan yang signifikan antar perlakuan, suhu esterifikasi $60^{\circ} \mathrm{C}$ lebih efektif dibandingkan dengan $50^{\circ} \mathrm{C}$, namun tidak ada perbedaan dengan suhu esterifikasi $70^{\circ} \mathrm{C}$ dan $80^{\circ} \mathrm{C}$. Walaupun secara grafik (Gambar 1) menunjukkan ada kecenderungan semakin tinggi suhu estrifikasi, kadar FFA akhir esterifikasi semakin kecil, tetapi berdasarkan pengolahan data statistik (Tabel 3) ternyata antara suhu esterifikasi 60 dan $70^{\circ} \mathrm{C}$ tidak ada perbedaan secara nyata. Suhu esterifikasi $60^{\circ} \mathrm{C}$ digunakan juga untuk esterifikasi minyak kedele oleh Canakci dan Van Gerpen (2001), Canakci dan Van Gerpen (2003), serta untuk minyak jarak pagar oleh Sudradjat et al. (2005). 


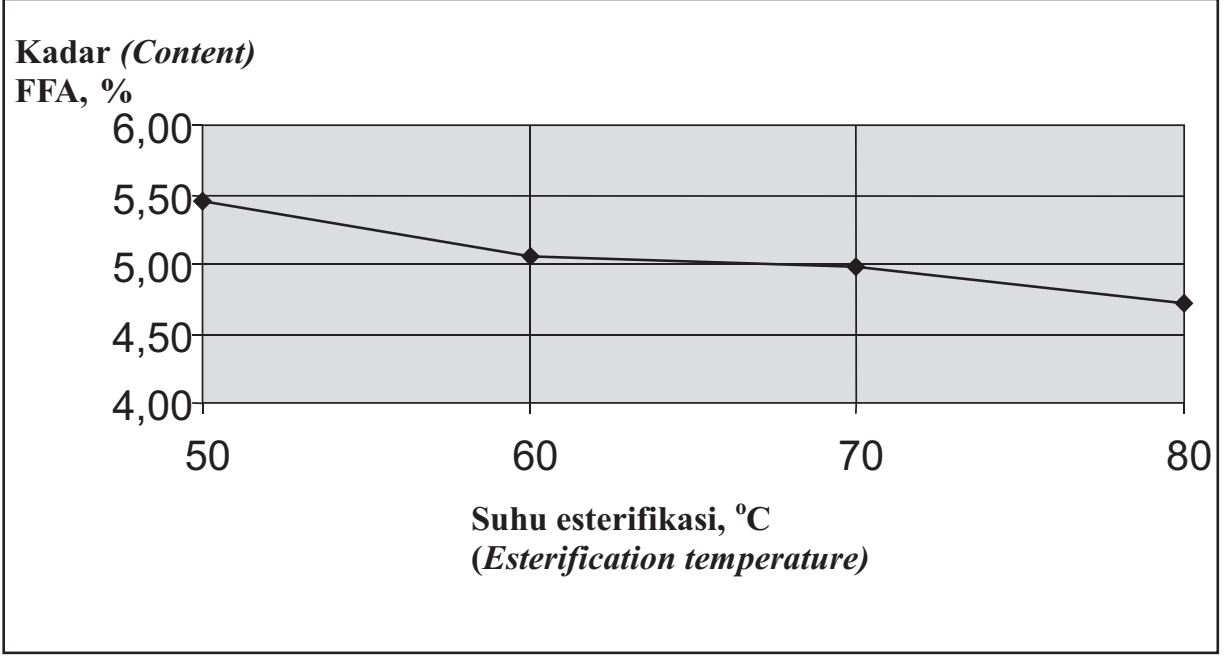

Gambar1. Rata-rata kadar FFA akhir esterifikasi pada berbagai suhu Figure 1. FFA Average content in the end of esterification at different temperature

\section{Pengaruh rasio mol (molekul)}

Kadar FFA pada akhir esterifikasi yang dilakukan pada suhu $60^{\circ} \mathrm{C}$, katalis $\mathrm{HCl} 6 \%$, waktu 60 menit, kecepatan pengadukan $400 \mathrm{rpm}$ pada berbagai rasio mol dapat dilihat pada Tabel 4 dan Gambar 2. Kadar FFA akhir esterifikasi menunjukkan perbedaan yang signifikan antar perlakuan, rasio mol metanol 20 : 1 lebih efektif dibandingkan dengan rasio mol yang lebih rendah namun tidak ada perbedaan dengan rasio mol yang lebih tinggi.

Secara grafik (Gambar 2), menunjukkan ada kecenderungan semakin tinggi rasio mol metanol semakin rendah kadar FFA akhir esterifikasi yang dihasilkan, tetapi berdasarkan pengolahan data statistik (Tabel 4), ternyata tidak ada perbedaan secara nyata rasio mol $20: 1$ dengan rasio mol yang lebih besar. Dengan demikian, rasio mol 20 : 1 merupakan rasio mol yang lebih baik untuk proses esterifikasi. Esterifikasi yang dilakukan oleh Canakci dan Van Gerpen (2003) terhadap lemak dengan FFA 39,6\% dengan 10\% asam sulfat dan rasio mol metanol 20 : 1 yang keduanya dihitung berdasarkan jumlah FFA, selama 1 jam pada suhu 55 $60^{\circ} \mathrm{C}$ menghasilkan minyak dengan bilangan asam $6,96 \mathrm{mgKOH} / \mathrm{g}(\mathrm{FFA}=3,5 \%)$ apabila setelah proses tersebut dilakukan pengendapan, kemudian bagian bawah diesterifikasi kembali dengan 10\% asam sulfat dan rasio mol metanol 40 : 1 oleh FFA kurang dari 1\% dengan bilangan asam 1,54 $\mathrm{mg} \mathrm{KOH} / \mathrm{g}$.

\section{Pengaruh konsentrasi katalis}

Kadar FFA pada akhir esterifikasi yang dilakukan pada suhu $60^{\circ} \mathrm{C}$, katalis $\mathrm{HCl} 6 \%$, waktu 60 menit, dan kecepatan pengadukan $400 \mathrm{rpm}$ pada berbagai konsentrasi katalis dapat dilihat pada Tabel 5 dan Gambar 3. Kadar FFA akhir esterifikasi menunjukkan perbedaan yang signifikan antar perlakuan, konsentrasi katalis $\mathrm{HCl} \mathrm{3 \%}$ dari FFA lebih efektif untuk 
Tabel 4. Rata-rata kadar FFA akhir esterifikasi pada berbagai rasio mol metanol Table 4. FFA average value in the end of esterification at different methanol mol ratio

\begin{tabular}{|c|c|}
\hline Rasio mol (Mol ratio) & $\begin{array}{c}\text { Rata-rata kadar FFA } \\
\text { (FFA average value), \% }\end{array}$ \\
\hline 0 & 31,0655 a \\
\hline 5 & 12,3464 b \\
\hline 10 & 9,3171 c \\
\hline 15 & 6,0509 d \\
\hline 20 & $5,3843 \mathrm{de}$ \\
\hline 25 & $4,6457 \mathrm{de}$ \\
\hline 30 & $3,9155 \mathrm{de}$ \\
\hline 35 & $3,8284 \mathrm{de}$ \\
\hline 40 & $3,7254 \mathrm{de}$ \\
\hline 45 & 3,2926 e \\
\hline 50 & 3,3247 e \\
\hline
\end{tabular}

Keterangan (Remarks) : Angka dengan kode huruf sama tidak berbeda nyata pada $\alpha 5 \%$ (Value with the same letter code is not significant at a 5\%). Bahan baku minyak nyamplung hasil degumming dengan kadar FFA 28,7\% (Raw material is callophyllum oil after degumming which contains FFA of $28.7 \%$

FFA, \%

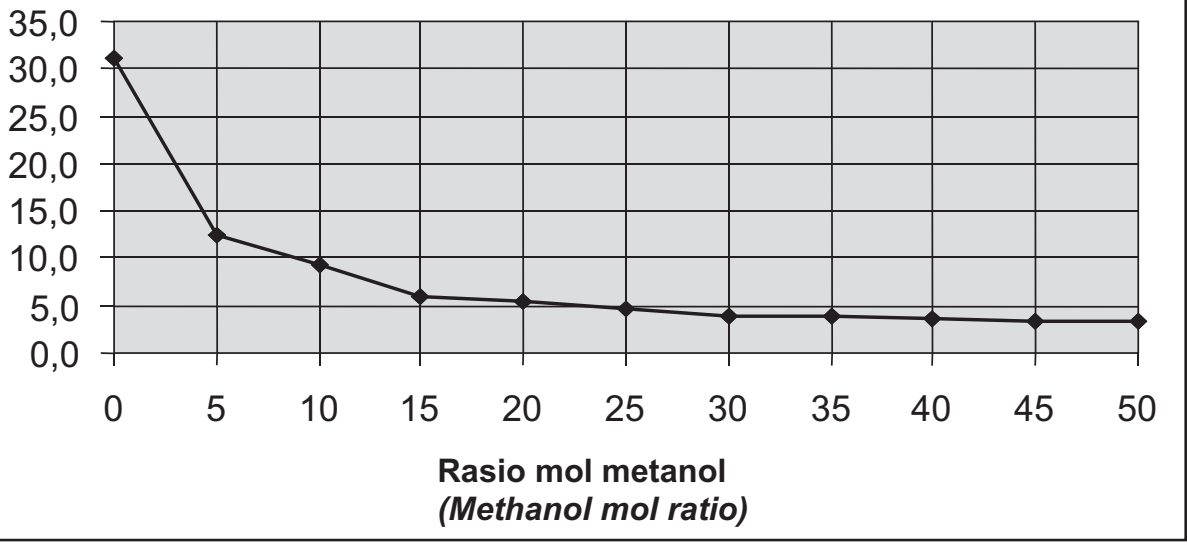

Gambar 2. Rata-rata kadar FFA akhir esterifikasi pada berbagai rasio mol metanol Figure 2. FFA average value in the end of esterification at different methanol mol ratio 
penurunan kadar FFA dan tidak ada perbedaan yang signifikan dengan penggunaan konsentrasi katalis $\mathrm{HCl}$ yang lebih besar (6\% - 18\%). Pada konsentrasi katalis 18\% kadar FFA pada akhir esterifikasi justru lebih tinggi. Karena tidak ada perbedaan antara penggunaan katalis $6 \%$ dengan 3\% begitu pula dengan penggunaan katalis yang lebih besar, maka konsentrasi katalis $6 \%$ yang dipilih karena apabila proses esterifikasi dilakukan pada skala kecil penggunaan katalis 3\% sulit dalam pengukuran.

Tabel 5. Rata-rata kadar FFA akhir esterifikasi pada berbagai konsentrasi katalis $\mathrm{HCl}$ Table 5. FFA average value in the end of esterification at different HCL concentration

\begin{tabular}{|c|c|}
\hline $\begin{array}{c}\text { Persentase } \mathrm{HCl} \text { dari } \\
\text { FFA minyak } \\
\text { (HCL percentage from oil's FFA,), \% }\end{array}$ & $\begin{array}{c}\text { Rata-rata kadar FFA } \\
\text { setelah esterifikasi }\end{array}$ \\
\hline 0 & (FFA average after Esterification), \% \\
\hline 3 & 14,3232 a \\
\hline 6 & 3,8502 b \\
\hline 9 & 4,0455 b \\
\hline 12 & 4,0659 b \\
\hline 15 & 4,1016 b \\
\hline 18 & 4,3024 b \\
\hline
\end{tabular}

Keterangan (Remarks) : Angka dengan kode huruf sama tidak berbeda nyata pada $\alpha 5 \%$ (Value with the same letter code is not significant at a 5\%). Bahan baku minyak nyamplung hasil degumming dengan kadar FFA 28,7\% (Raw material is callophyllum oil after degumming which contains FFA of $28.7 \%$

Secara grafik (Gambar 3), menunjukkan bahwa katalis sangat diperlukan dalam proses esterifikasi dibuktikan dengan perbedaan yang signifikan antara penggunaan katalis 3\% dengan tanpa katalis. Keperluan katalis untuk proses esterifikasi sangat kecil, hal itu dibuktikan tidak ada perbedaan yang signifikan penggunaan katalis 3\% dengan $6-15 \%$, penggunaan katalis 18\% justru menunjukkan kadar FFA akhir esterifikasi yang lebih besar. Menurut Canakci dan Van Gerpen (2001), esterifikasi terhadap minyak kedele yang mengandung FFA 20\% dengan menggunakan rasio mol metanol: FFA = 9:1 yang dilakukan pada suhu $60^{\circ} \mathrm{C}$ selama 1 jam dan katalis asam sulfat $5 \%$ dari FFA dapat menurunkan bilangan asam 41,33 menjadi 1,77. Sedangkan apabila kadar FFA awal 40\% (bilangan asam 91,73), setelah esterifikasi bilangan asam menjadi 18,82.

\section{Optimasi proses esterifikasi}

Optimasi proses esterifikasi dilakukan dengan metode permukaan respon (RSM). Hasil estimasi koefisien regresi dan analisis varian dari optimasi respon pengukuran kadar FFA akhir esterifikasi oleh tiga input variabel masing-masing yaitu rasio mol metanol (taraf percobaan $10: 1,20: 1$ dan $30: 1$ ), katalis $\mathrm{HCl}$ (taraf percobaan 3\%,6\% dan 9\%), serta suhu esterifikasi (taraf percobaan $45^{\circ} \mathrm{C}, 60^{\circ} \mathrm{C}$ dan $75^{\circ} \mathrm{C}$ ) disajikan pada Gambar 4, sedangkan hasil optimasinya disajikan pada Tabel 6 dan Gambar 5 dan 6. 


\section{Kadar (Content) \\ FFA, \%}

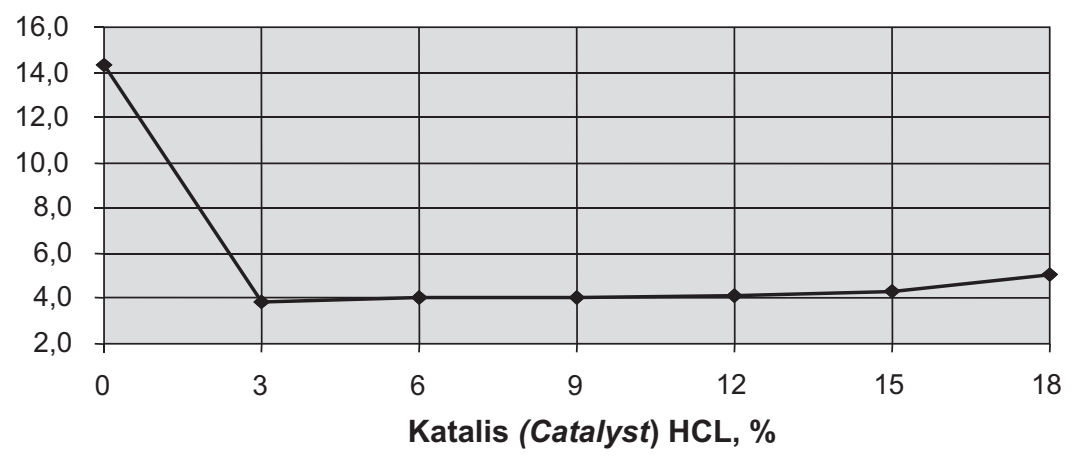

Gambar3. Rata-rata kadar FFA akhir esterifikasi pada berbagai konsentrasi katalis $\mathrm{HCl}$ Figure 3. Average of FFA content in the end of esterification processat different $\mathrm{HCl}$ concentration

Uji parameter model menunjukkan variabel rasio mol, suhu, rasio mol kuadrat, suhu kuadrat dan katalis kuadarat memiliki pengaruh penting terhadap FFA akhir esterifikasi, karena p-value pada variabel-variabel tersebut cukup kecil kurang dari 0,05. Nilai p-value untuk masing-masing variabel tersebut adalah rasio $\mathrm{mol}=0.002 ;$ suhu $=0.020$; rasio $\mathrm{mol}$ kuadrat $=0.000$; suhu kuadrat $=0,004$ dan katalis kuadarat $=0,061$. Berdasarkan Tabel 5 dan pengujian model, maka dapat ditarik kesimpulan bahwa optimasi esterifikasi didapatkan pada suhu $60^{\circ} \mathrm{C}$, katalis $6 \%$ dari FFA dan rasio mol metanol dengan FFA $20: 1$.

\section{Pembuatan biodiesel melalui proses esterifikasi}

Minyak nyamplung hasil esterifikasi masih mengandung FFA cukup tinggi yaitu sekitar $4,8 \%$, oleh karena itu proses estrifikasi dilakukan menggunakan dua tahap masing-masing esterifikasi dilakukan pada rasio mol metanol minyak $6: 1$, waktu 30 menit, suhu $60^{\circ} \mathrm{C}$, katalis $\mathrm{NaOH} 1 \%$ dan kecepatan pengadukan $400 \mathrm{rpm}$. Biodiesel yang dihasilkan mempunyai kualitas yang belum stabil dengan bilangan asam berkisar antara 0,6172 - 1,8403 mg $\mathrm{KOH} /$ gram dan viskositas pada suhu $40^{\circ} \mathrm{C}$ adalah $8,1-8,4 \mathrm{cp}(8,67-8,99 \mathrm{cSt})$. Komposisi metil ester biodiesel tersebut adalah metil palmitat $17,29 \%$, metil stearat $23,55 \%$, metil oleat $36,67 \%$ dan metil linoleat $22,49 \%$. 


\begin{tabular}{|c|c|c|c|c|c|c|}
\hline \multicolumn{2}{|l|}{ Term } & Coef & SE Coef & $\mathrm{T}$ & $\mathrm{P}$ & \\
\hline \multicolumn{2}{|l|}{ Constant } & 14,6349 & 2,80520 & 5,217 & 0,000 & \\
\hline \multicolumn{2}{|l|}{ Rasio mol } & $-0,3634$ & 0,08507 & $-4,272$ & 0,002 & \\
\hline \multicolumn{2}{|l|}{ Katalis } & $-0,3092$ & 0,28637 & $-1,080$ & 0,306 & \\
\hline \multicolumn{2}{|l|}{ Suhu } & $-0,1958$ & 0,07058 & $-2,775$ & 0,020 & \\
\hline \multirow{2}{*}{\multicolumn{2}{|c|}{ Rasio mol*Rasio mol }} & 0,0085 & 0,00115 & 7,353 & 0,000 & \\
\hline & & 0,0280 & 0,01323 & 2,114 & 0,061 & \\
\hline \multicolumn{2}{|l|}{ Suhu* Suhu } & 0,0019 & 0,00053 & 3,674 & 0,004 & \\
\hline \multicolumn{2}{|c|}{ Rasio mol*Katalis } & $-0,0035$ & 0,00525 & $-0,672$ & 0,517 & \\
\hline \multicolumn{2}{|c|}{ Rasio mol*Suhu } & $-0,0006$ & 0,00105 & $-0,589$ & 0,569 & \\
\hline \multicolumn{2}{|l|}{ Katalis*Suhu } & 0,0022 & 0,00350 & 0,640 & 0,536 & \\
\hline$S=0,4457$ & $\mathrm{R}-\mathrm{Sq}=$ & $93,4 \div$ & $\mathrm{R}-\mathrm{Sq}(\mathrm{adj})$ & $=87,4 \%$ & & \\
\hline \multicolumn{7}{|c|}{ Analysis of Variance for Kadar FFA } \\
\hline Source & $\mathrm{DF}$ & Seq SS & Adj $S S$ & Adj MS & $\mathrm{F}$ & $P$ \\
\hline Regression & 9 & 27,8877 & 27,8877 & 3,09864 & 15,60 & 0,000 \\
\hline Linear & 3 & 14,9092 & 4,1900 & 1,39667 & 7,03 & 0,008 \\
\hline Square & 3 & 12,7384 & 12,7384 & 4,24614 & 21,38 & 0,000 \\
\hline Interaction & 3 & 0,2401 & 0,2401 & 0,08003 & 0,40 & 0,754 \\
\hline Residual Error & 10 & 1,9861 & 1,9861 & 0,19861 & & \\
\hline Lack-of-Fit & 5 & 1,9293 & 1,9293 & 0,38585 & 33,92 & 0,001 \\
\hline Pure Error & 5 & 0,0569 & 0,0569 & 0,01137 & & \\
\hline Total & 19 & 29,8739 & & & & \\
\hline
\end{tabular}

Estimated Regression Coefficients for Kadar FFA using data in uncoded units

Term

Constant

Rasio mol

Katalis

Suhu

Rasio mol*Rasio mol

Katalis*Katalis

Suhu*Suhu

Rasio mol*Katalis

Rasio mol*Suhu

Katalis*Suhu
Coef

14,6349

$-0,363399$

$-0,309218$

$-0,195846$

0,00847999

0,0279677

0,00194431

$-0,00352917$

$-6,19167 \mathrm{E}-04$

0,00224167

Gambar 4. Hasil estimasi koefisien regresi dan analisis varian dari optimasi respon kadar FFA

Figure 4. Regression coefficient estimation and variant analyses of FFA optimation respons 
Tabel 6. Hasil optimasi respon permukaan kadar FFA akhir esterifikasi dengan input variabel rasio mol metanol, konsentrasi katalis dan suhu esterifikasi

Table 6. Respons of surface optimation of FFA in the end of esterification using variable input of methanol mol, catalyst concentrtation and esterification temperature

\begin{tabular}{|c|c|c|c|c|c|}
\hline \multirow[b]{2}{*}{ No. } & \multirow{2}{*}{$\begin{array}{c}\text { Rasio mol } \\
\text { metanol } \\
\text { (Methanol mol } \\
\text { ratio) } \mathrm{R}\end{array}$} & \multirow{2}{*}{$\begin{array}{c}\text { Katalis } \\
\text { (Catalyst) } \\
\mathrm{K}\end{array}$} & \multirow{2}{*}{$\begin{array}{c}\text { Suhu esterifikasi } \\
\text { (Esterification temp.) } \\
\mathrm{T}\end{array}$} & \multicolumn{2}{|c|}{ Kadar FFA (FFA Content) } \\
\hline & & & & $\begin{array}{l}\text { Percobaan } \\
\text { (Experiment) }\end{array}$ & Model * \\
\hline 1. & 10 & 9 & 75 & 8,484 & 8,311 \\
\hline 2. & 10 & 9 & 45 & 6,221 & 6,767 \\
\hline 3. & 10 & 3 & 45 & 6,146 & 6,215 \\
\hline 4. & 30 & 3 & 45 & 4,645 & 4,963 \\
\hline 5. & 10 & 3 & 75 & 6,695 & 7,355 \\
\hline 6. & 30 & 3 & 75 & 6,133 & 5,731 \\
\hline 7. & 30 & 9 & 45 & 5,607 & 5,091 \\
\hline 8. & 30 & 9 & 75 & 6,188 & 6,263 \\
\hline 9. & 20 & 6 & 60 & 4,751 & 4,800 \\
\hline 10 & 20 & 6 & 60 & 4,637 & 4,800 \\
\hline 11. & 20 & 6 & 60 & 4,849 & 4,800 \\
\hline 12. & 20 & 6 & 60 & 4,735 & 4,800 \\
\hline 13. & 20 & 6 & 60 & 4,850 & 4,800 \\
\hline 14. & 20 & 6 & 60 & 4,938 & 4,800 \\
\hline 15. & 3 & 6 & 60 & 9,232 & 8,586 \\
\hline 16. & 37 & 6 & 60 & 5,468 & 5,811 \\
\hline 17. & 20 & 1 & 60 & 5,365 & 5,048 \\
\hline 18. & 20 & 11 & 60 & 5,840 & 5,951 \\
\hline 19. & 20 & 6 & 35 & 5,232 & 5,052 \\
\hline 20 & 20 & 6 & 85 & 7,005 & 6,979 \\
\hline
\end{tabular}

Keterangan $($ Remarks $):^{*}=$ Model kadar FFA akhir esterifikasi $(Y)=14,6349-0,36339 \mathrm{R}-0,309218 \mathrm{~K}$ $0,195846 \mathrm{~T}+0,00847999 \mathrm{R} 2+0,0279677 \mathrm{~K} 2+0,00194431 \mathrm{~T} 2-0,00352917 \mathrm{RK}-$ 6,19167E-04RT +0,00224167KS 


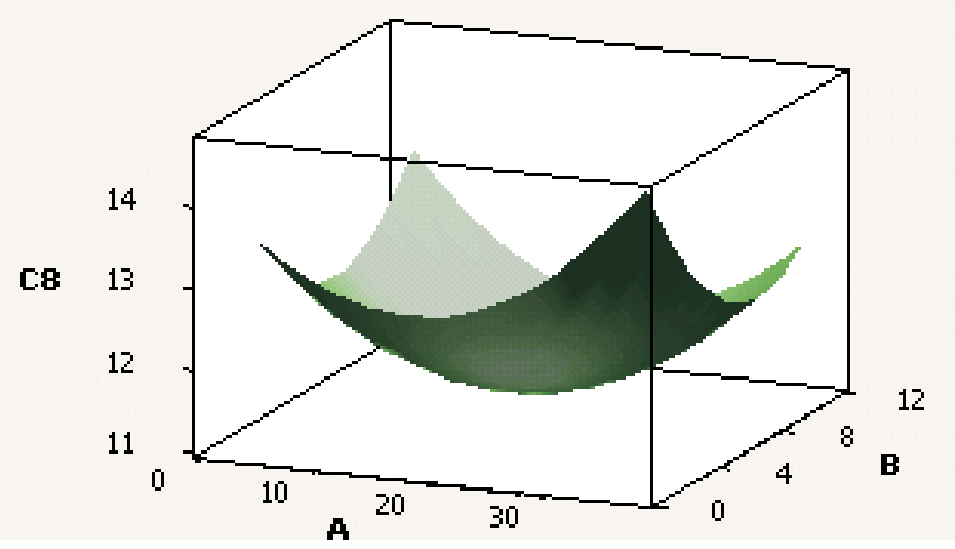

Gambar 5. Respon permukaan dari optimasi kadar FFA akhir esterifikasi dengan perlakuan rasio mol metanol, konsentrasi katalis dan suhu esterifikasi

Figure 5. Surface respons of FFA optimization in the end of esterification using variable input of methanol mol, catalyst concentrtation and esterification temperature

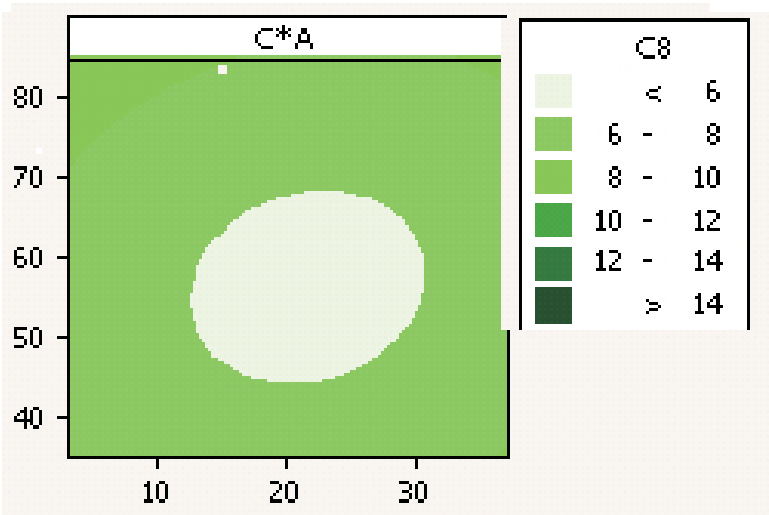

Gambar 6. Respon kontur dari optimasi respon kadar FFA akhir esterifikasi dengan perlakuan rasio mol metanol, konsentrasi katalis dan suhu esterifikasi

Figure 6. Contour respons of FFA optimation in the end of esterification using methanol mol ratio treatments, $\mathrm{HCl}$ concentration and esterification temperature 


\section{KESIMPULAN DAN SARAN}

1. Minyak nyamplung hasil ekstraksi mempunyai kualitas jelek, karena bilangan asamnya tinggi yaitu 59,9 mgKOH/g atau kadar asam lemak bebas (FFA) sebesar 29,5\%. Kondisi minyak yang demikian tidak dapat digunakan sebagai bahan baku biodiesel tanpa dilakukan proses esterifikasi terlebih dahulu.

2. Suhu esterifikasi $60^{\circ} \mathrm{C}$ tidak berbeda dengan suhu esterifikasi $70^{\circ} \mathrm{C}$, namun berbeda secara nyata dengan suhu esterifikasi $50^{\circ} \mathrm{C}$ dan $80^{\circ} \mathrm{C}$, hal itu menunjukkan suhu $60^{\circ} \mathrm{C}$ paling baik untuk esterifikasi.

3. Rasio mol metanol terhadap FFA $20: 1$ tidak berbeda nyata dengan rasio mol metanol yang lebih besar sedangkan rasio mol metanol FFA $15: 1$. Walaupun tidak berbeda dengan rasio mol $20: 1$ namun berbeda nyata dengan rasio mol $40: 1$ dan $45: 1$. Hal ini menunjukkan rasio mol metanol 20:1 paling baik untuk esterifikasi.

4. Konsentrasi katalis $6 \%$ dari FFA tidak berbeda nyata dengan konsentrasi katalis yang lebih besar dan konsentrasi katalis 3\%, namun berbeda nyata dengan esterifikasi tanpa katalis.

5. Proses esterifikasi minyak yang optimum diperoleh pada kondisi rasio mol metanol terhadap FFA $20: 1$, suhu $60^{\circ} \mathrm{C}$, dan katalis asam klorida $6 \%$ dari berat asam lemak bebas. Optimasi dengan metode respon permukaan menghasilkan model persamaan reaksi. Kadar FFA akhir esterifikasi yaitu : $(\mathrm{Y})=14,6349$ - 0,36339R - 0,309218K - 0,195846T + 0,00847999R2 + 0,0279677K2 + 0,00194431T2 - 0,00352917RK - 6,19167E-04RT + $0,00224167 \mathrm{KS}$.

6. Biodiesel yang dihasilkan dari transesterifikasi mempunyai kualitas yang belum stabil dengan bilangan asam berkisar antara 0,6172 - 1,8403 $\mathrm{mg} \mathrm{KOH} /$ gram dan viskositas pada suhu $40^{\circ} \mathrm{C}$ adalah $8,1-8,4 \mathrm{cp}(8,67-8,99 \mathrm{cSt})$.

\section{DAFTAR PUSTAKA}

Box, G.E.P., W.G. Hunter dan J.S. Hunter. 1978. Statistics for Experimenters. New York. John Wiley \& Son.

Canakci, M. dan Van Gerpen, J.V. 2001. Biodiesel From Oils and Fats with High Free Fatty Acids. Trans. Am Soc. Automotive Engine 44 : 1429 - 1436.

Canakci, M. dan Van Gerpen, J.V. 2003. A Pilot Plant To Produce Biodiesel From High Free Fatty Acid Feedstocks. Trans Asae 46 (4) : 945 - 954.

Dweek, A.C. dan T. Meadowsi Dweek. 2002. Tamanu (Calophyllum inophyllum) the African, Asian Polynesian and Pasific Panacea. International Journal of Cosmetic Science. 24 : 1 8.

Darnoko, D. dan M. Cheryan. 2000. Kinectics of Palm Oil Tranesterification in Batch Reaktor.J Am Oil Chem Soc. 77: 1263 - 1267.

Darnoko, D., T. Herawan dan P. Guritno. 2001. Teknologi Produksi Biodiesel dan Prospek Pengembangannya di Indonesia. Warta PPKS. 9 (1) : 17 - 27.

Freedman, B., E.H. Pryde dan T.L. Mounts. 1984. Variable Affecting the Yields of Fatty Esters from Transesterification Vegetable Oils. J Am Oil Chem Soc. 61 : 1638 - 1643. 
jURNAL Penelitian Hasil Hutan Vol. 25 No. 1, Februari 2007: 41-56

Haas, W. dan M. Mitterlbach. 2000. Detoxification Experiments with the Seed Oil from Jatropha curcas L. Indust Crops Prod. 12:111 - 118.

Heyne, K. 1987. Tumbuhan Berguna Indonesia. Balai Penelitian dan Pengembangan Kehutanan. Departemen Kehutanan. Jakarta.

Hui. 1996. Bailey'sn Industrial Oil and Fat Products V.1. A Wiley-Interscience Publication. New York.

Lee, K.T., T.A. Foglia dan K.S. Chang. 2002. Production of Alkyl Ester as Biodiesel from Fractioned Lard and Restaurant Grease.J Am Oil Chem Soc. 79 (2) : 191 -195.

Lele, S. 2005. Biodiesel in India. htttp/ / www.svlele.com/biodiesel 27 Juli 2005. India.

Martawijaya, A., I.K. Sujana, K. Kadir dan A.P. Soewanda. 1981. Atlas Kayu Indonesia. Jilid 1. Jakarta.

Mao, V., S.K. Konar dan D.G.B. Boocock. 2004. The Pseudo Single Phase, Base-Catalyzed Trans-methylation of Soybean Oil. J. Am Oil Chem Soc. 81 : 803 - 808.

Montgomery, DC. 1991. Design and Analysis of Experiments. New York : John Wiley \& Sons. New York.

Ozgul, S. dan S. Turkay. 2002. Vegetables Affecting the Yields of Methyl Ester Derived from in Situ Esterification of Rice Bran Oil. J Am Oil Chem Soc. 79: 611 - 614.

Pakpahan, A. 2001. Palm Biodiesel : Its Potency, Technology, Business Prospect, and Enviromental Implication in Indonesia. Proceedings of the International Biodiesel Workshop, Biodiesel Workshop, Enchancing Biodiesel Development and Use. Medan, Oktober 2 - 4, 2001. Jakarta: Ministry of Agriculture RI.

Priyanto, U. 2005. State of the Art Pengembangan Teknologi Bio Oil. P3TPSE-TPSA BPPT. Jakarta.

Reksowardoyo. 2005. Melaju Kendaraan Berkat Biji-bijian. Trubus November 2005 / XXXVI. Jakarta.

Sudradjat, R. dan D. Setiawan. 2003. Teknologi Pengolahan Biodiesel dari Minyak Biji Jarak Pagar. Laporan Penelitian Hasil Hutan. Sumber Dana DIK-S DR Tahun 2003. Pusat Litbang Hasil Hutan. Bogor. (Tidak diterbitkan).

Sudradjat, R., J. Indra dan D. Setiawan. 2005. Optimalisasi Proses Estrans pada Pembuatan Biodiesel dari Minyak Jarak Pagar (Jatropha curcas L.). Jurnal Penelitian Hasil Hutan 23: 239 - 337. Bogor.

Sudradjat, R. 2006. Memproduksi biodiesel jarak pagar. Solusi hasilkan biodiesel berkualitas tinggi. Penerbit Penebar Swadaya Seri Agritekno. Jakarta

Tri Budiman, B. 2005. Penggunaan Biodiesel sebagai Bahan Bakar Alternatif untuk Kendaraaan Bermotor. Makalah Seminar Star UP Program Capital. Jakarta, 12 Agustus 2005.

Tyson, K.S. 2004. Energy Efficiency and Renewable Energy. US Departement of Energy. New York. 